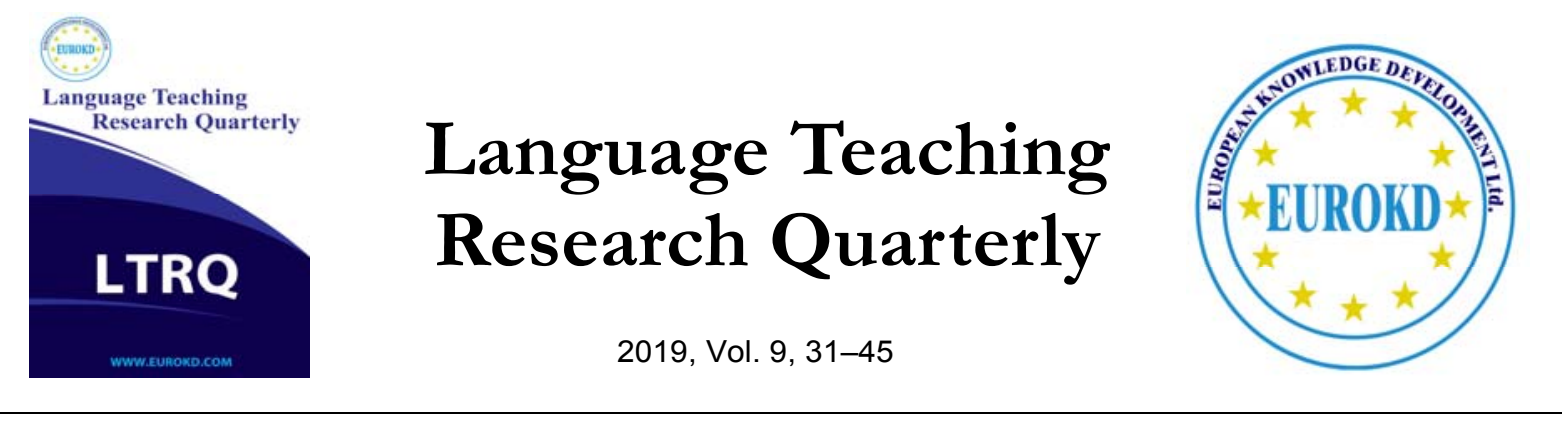

\title{
EFL Learners' Misconceptions or Erroneous Beliefs about Language Learning: An ESP Context
}

\author{
Zahra Akbari \\ Isfahan University of Medical Sciences, Isfahan, Iran
}

Received 22 September 2018 Accepted 01 February 2019

\begin{abstract}
The beliefs that learners have regarding language learning have been the subject of numerous research studies. But not enough attention has been paid to investigating the nature of learners' beliefs shaped in the process of foreign language learning. Beliefs can affect the learners' language success as well as their learning outcome and behavior. It is important to gain deeper insight about EFL students' perceptions and understand their beliefs since it helps teachers to become familiar with learners' use of learning strategies based on which they can plan a more appropriate language instruction. This study is an attempt to investigate language learning erroneous beliefs and misconceptions of 67 MSc ESP students of midwifery, operating room, and nursing in Isfahan University of Medical Sciences, Iran. They were selected through purposeful sampling and their language learning behaviors were observed by the researcher throughout two consecutive semesters while passing their ESPI and ESPII. Furthermore, data were collected using unstructured field notes and semi-structured interviews. The collected data were analyzed through thematic analysis, the data were coded in line with the research question, and themes as well as sub-themes, were extracted. The findings of this study suggest that action should be taken by the ESP teacher to modify learners" erroneous beliefs, eliminate negative beliefs, and evolve their simplistic self-instruction beliefs. The findings of the study can inform syllabus design, curriculum development, teacher practice, and material preparation.
\end{abstract}

Keywords: Misconceptions, EFL learners, ESP Context, Language Learning Process

\section{Introduction}

Learners bring to the language classroom a complex network of attitudes, experiences, expectations, beliefs, and learning strategies. In this study, learners' beliefs have been defined as 
1) Learners' "mini theories" of second/foreign language learning (Hosenfeld, 1978. Some of these beliefs have even become theories the learners strongly believe of their usefulness since they have been validated by experience due to the erroneous teaching strategies followed by EFL teachers at schools and even sometimes at university (Abid, 2012a).

Wenden (1999, p.436) assumes that learners' beliefs can be both conscious and unconscious at the same time. These beliefs can be acquired unconsciously through observation and imitation and consciously through listening to teachers, parents, or even partners when giving advice about how to learn.

Learners bring various language learning beliefs into the classroom, among which, some are facilitative of language learning, while others are misconceptions. They also seem to be stable, strongly held, and resistant to change since they are formed and maintained by a complex social and cultural system and they are unique to individuals (Asbjornson, 1999, p. 1 .

The deeply held beliefs that most learners appear to have about second language learning have received a lot of attention in recent years. Researchers have found that second language learners come to the language class with some preconceived beliefs about language and language learning and these beliefs can indicate what expectations learners have and what actions in their language learning they will take (Horwitz, 1987; Wenden, 1987). It is said that learners' beliefs cause them to approach a specific language learning task differently and account for the individual differences observed even among learners with similar language proficiency (Mori, 1999).

The investigation of beliefs which inform different behaviors in the language classroom is useful for gaining firsthand insight into learners' conceptual frameworks in second or foreign language acquisition (Bernat \& Gvozdenko, 2005).

A great deal of studies have dealt with learners' beliefs about language learning. ( Barcelos, 2003) classifies these studies into three groups according to the research paradigm used. A first research paradigm is called the 'normative approach'. Typically, normative studies on learners' beliefs make use of Likert-type questionnaires in which learners are asked to indicate to what extent they agree or disagree with a set of statements on language learning.

The second paradigm is the 'metacognitive approach' in which beliefs are defined as metacognitive knowledge (Wenden, 1987). Finally, the third and most recent research paradigm is the 'contextual approach' in which the aim is to get insight into learners' beliefs in specific contexts rather than to arrive at a general picture of beliefs about second language learning. All approaches have drawn attention to the importance of beliefs about SLA in applied linguistics and have described the sorts of beliefs about SLA that we may encounter in language classrooms. However, more grounded studies help us understand how students actually use beliefs to interpret situations and make decisions in their language learning process in the unique context of language classrooms. Some studies within the contextual approach have begun to investigate this aspect but we still know very little about the functions of beliefs in the culture of the classroom. Researchers have recently suggested that open-ended interviews and classroom observations can help us have a more fine-grained picture of students' beliefs about SLA(Kalaja 
\& Barcelos, 2003). Beliefs about SLA research have to move beyond a simple description of beliefs as predictors of future behaviour to an investigation of beliefs in context( Barcelos, 2003).

Learners' beliefs about language learning have been investigated from different perspectives. Most studies surveyed learners' beliefs in general in order to see what kind of influence these beliefs may have on their learning the foreign language. Other studies investigated learners" beliefs in relation to individual characteristics that may affect the process of language learning like anxiety, learners' attitudes, culture, proficiency, communicative competence, language learning strategies, learner autonomy, and gender. Finally, language learners' beliefs are also studied together with the ones held by their teachers so as to find out what influence the similarities or differences between the two systems of beliefs may have on language learning and teaching process (Yu, 2007) and (Erlenawati, 2002a).

Awareness of the complexity of learners' beliefs and expectations can help us understand the realities of the early stages of self-instruction in language learners ( Hurd, 2003). Analyzing the learning beliefs of EFL learners as well as the processes they are engaged in while shaping these beliefs and making them aware of their wrong beliefs might be helpful to direct them in the right path, diminish the length of time committed to language learning, and promote the depth of language learning.

More research is clearly needed in order to arrive at deeper understanding of the complexity of learners' beliefs about the foreign/second language learning. It seems that still little is known about the variations of language learning beliefs among the groups of language learners (Fujiwara, 2014).

To the best of my knowledge, no study has been carried out on the nature of erroneous beliefs formed as self-instructions in the process of foreign language learning especially in an ESP context. Self-instructions are the processes learners establish for themselves to engage with the target language and to continue to develop target language skills (White, 1999). It has also attempted to illuminate the main factors that helped learners arrived at this complex nature of beliefs.

\section{Methodology \\ Participants}

The student population of this study was 66 male $(n=9)$ and female $(n=57)$ students majoring in midwifery, nursing, and operating room at MSc level in Isfahan University of Medical Sciences. All the students studying in six groups (four groups, nursing students [ $\mathrm{n}=22]$; one group, midwifery students $[n=12]$; and one group, operating room students $[n=12]$ ) were selected by means of census method. Their ages ranged from 29 to 34. The participants of the present study were ESP students studying ESP I and ESP II (two credits each) in the first two consecutive semesters in the school of Nursing and Midwifery. They studied reading comprehension (of their main references) in ESPI and translation of their academic texts (for educational purposes) in ESP II while paying attention to different linguistic structures, contextual features, and specialized as well as non-specialized vocabulary involved in their texts. Based on OPT results 
and teachers' (language teacher and content teacher) opinions of students, the English proficiency of the participants was estimated to be lower intermediate. Their average English score in MSc entrance exam was below 30\%. They had passed an ESP course (two credits) at their BSc level. They were accepted at MSc level after 5 to 15 years from their graduation. They had not attended any language institutes during this period. And they all have been working in the hospitals since their graduation.

They have developed beliefs about language learning along all the years they spent learning English starting from the secondary schools till academic education at university.

\section{Data Collection}

Discovering students" attitudes and beliefs is possible; as it is generally accepted that language learners are capable of bringing this knowledge to consciousness and articulating it (Kalaja \& Barcelos, 2003; Hsenfield, 2003). To this end, dialogues between learners and teachers regarding language learning beliefs are central (Wang, Spencer, \& Xing, 2009). When learners grow up and gain "cognitive maturity", they may reflect such beliefs on their process of language learning and they may even revise earlier assumptions or develop new ones. By doing this, learners bring their beliefs into consciousness and they may talk about or defend them since they believe them to be true especially if these beliefs have been validated by experience (Wenden, 1999).

Previous studies h surveyed the learners" beliefs about the four language skills using Horwitz ( 1988) Beliefs about Language Learning Inventory (BALLI) Questionnaire. It was developed to assess students' opinions on a variety of issues and controversies related to language learning. However, in this study, the students' language learning behaviors were observed by the researcher throughout two consecutive semesters while passing their ESPI and ESPII to elicit/reveal the misconceptions developed in them in the process of foreign language learning. Furthermore, data were collected using unstructured field notes regarding dialogues between teacher and students and semi-structured interviews with the learners. The collected data were analyzed through thematic analysis, the data were coded in line with the research question, and themes as well as sub-themes were extracted.

\section{Results}

Wrong beliefs shaped in the process of language learning in an ESP context are as follows:

Learning is equal to memorization (either of decontextualized vocabulary items; that is, bilingual or ideally monolingual lists, grammar rules or cliché phrases or sentences). In other words, students' willingness to learn may stem from a fear of getting low marks and that they defined learning as memorizing information and preparing for tests (Tsai \& Kuo, 2008).

Llearning English is very difficult and almost impossible within the limitations of an EFL context. It leads to the view that they are not able to learn English. Learning a foreign language could either be problematic or simplistic. For those who have learnt a foreign language (e.g. English) for a long period of time without any significant progress it might be discouraging (Wahyudi, 2014). 
Learning English means just learning to speak English. But how is it possible to speak a language when they do not have contact with its native speakers? As they live in an EFL context, they must realize that speaking is not most likely to be their priority and they must focus on the task-based learning in learning language skills based on their academic and professional needs. Language skills can be separated from each other and learned individually. It must be clarified to the students that language skills are not separable while the focus of attention may vary from one skill to another depending on students' language needs and learning context. A foreign language can be learned in a short time only if do they know a limited set of rules, extensive vocabulary items, formulas and cliché's. Through more exposure to language, they must realize that language is not composed of a set of rigid rules and vocabulary items; these rules and vocabulary items have variations in use depending on the context in which they are used. Rules which are elicited or explicitly stated by the teacher imply that there are no exceptions to them. As they have limited exposure to language and tend to have the easiest way to learn the language, they are most likely to make overgeneralizations based on the the limited input they encounter or what they hear from their teachers. There is a one to one equivalence between English and Persian language systems as far as their vocabulary items, grammatical rules and mental frameworks are concerned. Therefore, they try to use mental translations for all of the components in the target language including lexical items, grammatical rules and cultural concepts relying on their native language corresponding equivalence.

Every word is considered as a unit of meaning. It is decontextualized and looked up in the dictionary as if a wall is built around it to be disconnected from the rest of the sentence and is understood individually. As they are not familiar with meaningful chunks and the rich information potenials in the monolingual dictionaries, it results in word-for-word translation and not missing any single word especially in translation and reading comprehension. Words are related to each other according to the linear order they are arranged in a sentence. In this way, they miss the meaningful chunks which are separated from each other in a sentence such as verbal phrases and fail to recognize the syntactic relations between items at different hierarchical levels. Learning occurs from parts to whole. That is, the meaning of a sentence is the sum of the meaning of its parts. The relationship between words, sentences, paragraphs and the interrelationships among all of them and the topic of the text is usually disregarded. To understand the meaning of a sentence, the meaning of every single word should be understood; that is, no single word should be ignored. In this way, the writer's intended message is usually misinterpreted. Committing mistakes is considered as a sin which leads to embarrassment, stress and anxiety and avoidance to take part in class activities.

Giving synonym means giving one word as equal to another word in meaning. They do not think of other ways to define the new word such as explaining its meaning in simple words in English or giving its opposite. Synonyms can be used interchangeably in every context (e.g., damage vs injury, include vs contain, develop vs improve). This results from their lack of knowledge of collocations in use. In giving a synonym for a new word, only its meaning is important to be taken into account. They disregard its other features such as part of speech, 
pronunciation, derivations, and collocations For example: "Adults average [=on average] about two to four colds a year". They first translate the word into Persian and then find an equivalent for the given Persian meaning in English. In translation, the aim is to transfer every single word to another language rather than convey its intended meaning. Every single word has the same meaning in different contexts (and for the familiar words it is always the meaning he/she learned for the first time). For example: "The risk of developing[improving] heart disease is reduced.", "It often is used for rehabilitation since[from the time] the exact area of muscle weakness can be isolated."). function)

Every single word has the same part of speech in different contexts.(e.g., change,

Vocabulary is more important than grammar in learning English.

Grammar is a set of rules which is just used to do grammatical exercises and/or do tests.

Grammatical rules which they have already learned have no exceptions and are generalizable to different contexts.

Passive sentences do not have any subjects. They begin with an object.

The first verb they encounter in a sentence is the main verb of the sentence. For example: "The reason everyone has those stubborn areas is because each of us is born with a genetic pattern of fat storage".

The first meaning in an entry whether in monolingual or bilingual dictionary is always the best meaning for a new word. For example, "Most people give up[=yield] too early in the workout."

The meaning of a word is the only thing needed to be looked up in a dictionary.

Looking up the meaning of the new words in a bilingual dictionary is the best and the most convenient way to arrive at their meanings.

Word-for-word translation is the best way of learning English as far as achieving the immediate goal of passing the course with regard to the multiple-choice format of the exams is concerned. The participants employ translation as a learning strategy to comprehend, remember, and produce English and they depend heavily upon translation in the process of learning and acquiring English as a foreign language ( Ridha, 2014). As they are not proficient in English, they insist on translation for a better understanding; to ensure that their understanding is clear and accurate. Owing to the translation method students are exposed to during their primary education, these students believe in its effectiveness (Chai, 2013).

All of these beliefs imply that they either learned the teaching points not correctly (i.e., they had surface learning) or learned them not thoroughly as the new points had not been taught in a systematic, comprehensive and synergic manner at the same or different educational levels. In addition, the input provided for the learners have not been rich enough to achieve rich intake. So, they have gradually developed mental frameworks to interpret the pieces of evidence (input) they encountered in accordance with the mental concepts they had already formed based on their limited exposure to language in an EFL context.

Factors played a role in this study to shape and structure EFL learners' beliefs are as follows: 


\section{The role of teachers}

They use Persian to teach English (either out of lack of competence in English and/or their students' low language proficiency level). Professionalism essentially means helping students master the textbook(s) being used and perform successfully in the final exam which does not necessarily represent and reflect quality learning (the writer) (Bransford, Brown, \& Cocking, 2000).

Teachers usually lack the required knowledge (i.e., proficiency level) and skills (i.e., assessment skills and language teaching/learning strategies) to help students' achievement and satisfaction in learning as they have not been trained in this regard. Furthermore, due to time constraints, teachers cannot enhance students' proficiency considerably, revise their misconceptions, give them the necessary feedback to correct their error, and prepare them for life-long learning. Teachers also do not usually receive the required official support to teach what and how they believe in and are usually under the pressure of weak students which act as "brakes" on their way and negatively affect the teacher's teaching evaluation form (i.e., judge their performance unfairly). Therefore, the relationship between teachers' beliefs and practice is complex, highlighting the influence of both macro- and micro-contexts ( Li, 2013).

On the one hand, the commonly used method is usually teacher-oriented and on the other, teachers usually do not play a significant role in assessment because of top-down managerial approaches to assessment and education system.

Challenges that exist in EFL teaching profession are not only of the educational type. There are also economic, temporal and social challenges. Therefore, attributing the existing problems to an individual factor which may play a role in students' learning is unwise. No one is to blame now because everyone, from students and their parents to the high officials in the country, has somehow a hand in creating the situation (Razmjoo \& Mavaddat, 2016).

\section{The role of learners}

Most of the students ( $95 \%$ or more) in paramedical fields either at BSc or MSc enter the university with very low scores (from $0 \%$ up to $30 \%$ ) with few students (5\% or fewer) above $50 \%$ (up to $70 \%$ ). At BSc level, students who hold below $40 \%$ have to pass a pre-university English course which is two units. But it is not enough to learn the minimum English learning points required (such as study skills, special and literal meaning of the new words, the use of grammatical points in facilitating development in different skills, etc.) to lay a solid foundation for the GPE and ESP courses they are supposed to pass in the following semesters. However, for students at MSc level, even such a small chance is not provided and students with different proficiency levels (as far as their English scores in University Entrance Exam is concerned) and large intervals between BSc graduation and MSc acceptance (i.e., from 3-15 years resulting in significant forgetfulness) are accepted at MSc level. At both levels, the students' scores in their specialized subjects (usually above 70\%) is the major criterion for being accepted in the university no matter what their English score is. Thus, the students' low English proficiency 
level causes a lot of problems for both the teacher and the students as far as covering the assigned syllabus within its due time is concerned.

In EFL contexts, students hold strong instrumental motivation for learning English, possibly, because of self-imposed or other-imposed pressures (Ghobadi Mohebi \& Khodadady, 2011). If the motivation to learn an L2 is to pass a class or receive an academic credit, then once completing this goal, there may be no point for an individual to continue studying after receiving their mark.

In an EFL context, learners are not motivated independent learners and learn most of the key points through trial and error and try to develop rules out of the inadequate input received in classroom context. Most of them do not have a reliable reference to help them resolve their learning problems except their English teacher who does not usually have the time to help them whether inside or outside classroom. In addition, forgetfulness usually occurs due to time intervals between different educational levels and the kind of teaching, learning as well as evaluation methods used (which usually focus on surface learning instead of deep learning, critical thinking, creativity, collaboration and communication).

As they do not have critical thinking skills, problem solving skills, study skills, listening skills, enough self-confidence (mainly due to their low language proficiency), positive attitude towards learning English (mainly due to disturbing experiences during learning English especially annoyed by their teacher and/or peers), do not know how to learn, do not know how memory works, how the learning process occurs, do not receive enough input inside and outside the classroom, do not have enough practice and recycling, are not exposed to language systematically and continuously, have lower intermediate language proficiency levels and are affectively under the pressure of learning English, instrumentally motivated, usually have objective summative tests based on the memorization of course content, receive the fewest number of formative tests and self- and peer and teacher feedback especially due to time constraints to cover the assigned syllabus, not have internal locus of control (Rotter, 1996), they are usually afraid of making mistakes, give up easily and in general do not enjoy learning.

\section{The role of assessment technique}

The goal of assessment is grading. There are three national examinations for entry to various levels of university education at the end of high school, BA, and MA programs. These highstakes examinations (i.e., multiple-choice tests) shape the future of Iranian students, having a huge impact on the learners' lives and educational opportunities. However, no written report is available on the psychometric characteristics of these tests to give feedback to the learners as well as teachers on the learners' weaknesses and strengths. Moreover, multiple-choice questions do not check students' learning proficiency, direct them toward memorization with short-term effectiveness instead of deep learning, ultimately the core components which are spelling, pronunciation, fluency, usage and different learning strategies cannot be assessed in this way. 
Standardized tests and/or multiple choice questions that are currently used to provide information about students' learning are highly questionable in terms of validity and content and do not develop learners' productivity and creativity in language learning.

The high pressure of preparing for examinations and the high consequences for passing or failing probably puts undue pressure on the students; this can explain students' negative attitude towards assessment as well as language learning and their wrong beliefs. However, at different educational levels, some other forms of assessment such as portfolio assessment may be administered.

\section{The role of Iranian educational system as an EFL context}

Since the language of instruction in the universities is Persian, there is no strong feeling toward the need for English, especially at the undergraduate level. In fact, the few English units are the only exposure that university students have in their undergraduate studies. At the graduate level, too, English is considered a tool to enable students to access the materials written and published in English (Farhady \& Hedayati, 2009). However, they either get them translated or use the translation version available.

There is not enough exposure to language both inside and outside classroom. In order to consolidate classroom learning, sufficient time should be devoted to repetition and practice inside and outside the classroom. Therefore, student workload in each semester (i.e., number of units to be covered) should be reduced and English courses should be added to the educational curriculum in each semester.

Even technical words are not required to be written in English in medical records in clinical settings. Using English neither in educational system nor at workplace is among the priorities. Additionally, there is a gap between what teachers (including content and language teachers) do in real contexts of teaching/learning, what researchers say and what policy makers decide about. And what is appealing to the students might not be appealing to the government (i.e., policy makers).

Above all, there is little or no cooperation between language teachers and content teachers in developing the English materials and no harmony as well as synergy between what English teacher does in the classroom and what content teachers and/or the authorities in the workplace require students to do as far as the required English activities are concerned. This decreases the students' motivation significantly to take part in English class activities let alone help them promote and consolidate the depth of their learning and spend time to modify their wrong beliefs. To top it all, sometimes non-specialists (i.e., content teachers) take over or insist on taking over teaching ESP courses and they claim to have the required competency mainly based on their experience of being abroad for a limited period of time. And it considerably decreases the quality of teaching and learning English.

In addition, English teachers have a set of minimum expectations that should be fulfilled in the classroom by learners and act on those expectations but learners resist adhering to them as they feel they are not required to do so in real situations including their academic or clinical settings. 
So, the actual student achievement in English courses is low compared with their English teachers' expectations. It may be because of the fact that students tend to handle the academic and clinical situations mainly with the knowledge of technical words and abbreviations they acquire in their specialized courses.

The teacher tries to dispense the required knowledge and information as he/she is interested in students' future progress while students exhibit minimum motivation and appreciation. In other words, there is little or no harmony between the teachers' teaching creeds (Ahmad, Hussain, \& Radzuan, 2017) and the learners' learning demands/expectations. This acts as a barrier between student and teacher and downgrades the teaching/learning outcomes.

The role of materials

The textbooks focus on teaching points not on delicacies of language use, contextualization of the language and language learning strategies. The prescribed textbooks are grammar-oriented; the national exams are likewise structural in orientation. There are teaching points (e.g., structures) that not only the students but also native speakers do not use frequently. It is not strategy-based. It does not teach the basic required skills such as study skills. It does not also teach the required language learning skills in EFL contexts, i.e., reading and translation skills let alone other skills which are required depending on students' needs and objectives. Furthermore, as the materials are compiled by a non-native speaker, they usually contain some linguistic and non-linguistic errors.

In some fields, such as nursing, midwifery and operating room, especially at postgraduate level, there are no textbooks and no syllabus. On the other hand, in the fields in which a syllabus is written, it is too big to be applied in one semester or it is not based on the learners' needs. Teachers are not usually aware of the existing syllabus for their given English course or they do not usually have a lesson plan prepared for each class session based on the existing syllabus. As they think the starting point should not be the syllabus but the learners' proficiency level. The course book does not usually have a guideline for teachers to follow and also the ultimate goals to be achieved at the end of each lesson are not clarified and exactly defined. Therefore, each teacher may have a different approach to teaching the same course book based on his/her presuppositions.

\section{Discussion}

The present study has addressed two important issues: first, identifying what beliefs Iranian ESP students at MSc level have developed during learning English and secondly, discussing the potential impact of different factors on how these learners would approach language learning and form the resulting beliefs during the process of language learning.

The findings of the study showed that Iranian postgraduate students held stable firm beliefs about English language learning which had already been developed during their educational experience of learning English and several factors have had potential impact on the development of these beliefs. 
Although their instructor made a lot of efforts to modify their beliefs, there was not a great shift in their beliefs during the two consecutive semesters. This might be due to the fact that a period of two semesters of instruction was too short for them to change their beliefs about English language learning and that their instructor could not eliminate/control all the intervening factors played a role in the establishment of these beliefs. But their instructor's efforts were not quite fruitless. The significant achievement was helping students change their attitude and perspective toward learning English and increase their motivation and self-satisfaction by empowering them with the knowledge and expertise to meet their educational as well as professional language needs.

External motivators, such as need for employment (Bernet, 2004) in higher education system as instructors and continuing education at Ph.D level predominated MSc students, can be used to help these students modify their beliefs in spite of all the pressures imposed on them (i.e, working, studying as well as managing a family).

In line with the study carried out by (Sakui \& Gaies, 1999), this article can inform efforts at policy and program evaluation. Major changes in the policy and practice environment are expected to result in belief changes. Understandably, within the educational setting of Iran, greater value is placed on examination and testing than any other form or method of assessment. The idea of using multiple-choice tests for evaluating students' achievement is no longer acceptable. But caution should be exercised before any swift and unplanned change can be practiced (Farhady, 2006).

Assessment external to classroom (i.e., University Entrance Exam at different educational levels) should provide a reliable, realistic cut-off point for students' language proficiency in different fields of study and assessments internal to the classroom should be integrated into teaching and learning in a cyclic manner and should provide proper conditions for learners to satisfy their educational, research and clinical needs in their intended contexts. Its main purpose should be to obtain information about learning gaps and to close them as much as possible in learning contexts. All of these delicate points should be taken into account in designing courses and developing the educational curriculum if it is intended to have productive courses.

We should know enough about the nature of incoming students' beliefs to implement effective curricular interventions addressing those beliefs (Mantle-Bromley, 1995, p. 377). There must be a serious re-viewing of the Iranian curriculum in English language teaching in order to broaden the skills required for students to learn in school. Curriculum designers should provide a learning environment that continuously promotes self-monitoring, self-evaluation and reflection on progress (Tsai \& Kuo, 2008).

Educational settings play a major role in moulding EFL students' beliefs. Students interpret the instructional points presented in the classroom against their firmly shaped mental framework to the extent that it seems they do not exactly hear what the teacher says; they hear what they want to hear as if they do not have the required listening skills. We should acknowledge learners and teachers of the learning processes occurring and also of the affective/intervening factors involved which can accelerate or slow down the process of language learning. 
There is evidence of a progressive construction and crystallization of beliefs about learning (Cantwell, 1998; therefore, restructuring of these beliefs is very difficult and takes a lot of time and it is the critical role of highly qualified, creative, interested, committed, and determined teachers to implement proper intervention measures.

Accomplishment is achieved only if do we sensitise teachers in EFL environments to the types of beliefs learners may hold and to the possible consequences of these beliefs for foreign language learning and instruction(Erlenawati, 2002b).

Language teachers were assumed to be able to simply take on the role of educational "psychotherapists" and rid students of their "irrational" and "destructive" beliefs (Bernat \& Gvozdenko, 2005); provided the required facilities are available to them and the current barriers are removed. The message for the teachers is that students' beliefs or mentality can be shaped or reshaped or enriched if there are meditational tools such as facilitating language learning/teaching process, enhancing active participation of the learners in classroom activities through thoughtful, inspirational words of encouragement, encouraging self-feedback (reflection), peer corrective feedback as well as teacher feedback respectively, recycling language learning activities and checking constantly what they have understood both in class and in exam papers to help them overcome their fear of learning English and developing students' understandings of the nature of their work.

As there are cyclical relationships between learners' beliefs and strategy use (Yang, 1999), syllabus designers and material developers are also recommended to include learning strategies, (self-)study skills, critical thinking and problem solving skills within the syllabus. If these are reinforced by the course books all through the syllabus, students' beliefs are formed and reformed more systematically (Mohammadi, Birjandi, \& Maftoon, 2015).

Additionally, students with better understandings of the learning process (e.g., how memory works in surface vs deep learning, the role of different kinds of errors including developmental errors vs interference errors, the role of affective factors and erroneous beliefs on learning process) are better at perceiving the nature of learning, more open to learning, have higher expectations about what they will get from learning and exhibit less anxiety in relation to learning (Kara, 2009).

\section{Implications}

When identifying learners' erroneous beliefs and guiding them in the language classroom, their frustration can be alleviated. Investigating what learners believe about language learning is "a process of (self-) discovery which involves the learners themselves as much as the teacher" (Tudor, 1996, . It enables the learners to develop "a critical and informed awareness of learning options " (Wenden, 1986,p.199).

These deeply rooted erroneous or conflicting beliefs about language learning should be eliminated since they impede the learners' language learning progress and lead to dissatisfaction with the course, frustration, anxiety and stress in the learners. It is, therefore, essential for language teachers to help shape their students' beliefs towards the achievement of success in 
language learning. They reflect these beliefs in the process of language learning and the teacher should help them revise their previous assumptions and develop new ones. The teacher should also help them develop insightful beliefs about language learning processes, their own abilities, and the use of effective learning strategies.

On the other hand, students can have "mistaken," uninformed, or negative beliefs that may lead to a reliance on less effective strategies and lack of autonomy in learning and may likely lead students to the conclusion that they do not possess the necessary abilities required to learn a foreign language which inhibits learners' perceptiveness to the ideas and activities presented in the language classroom especially when the activities are not consistent with the learner's previous experience (Bernat \& Gvozdenko, 2005). Through strategy training and consciousnessraising, teachers can develop greater flexibility in learners' ways of approaching English. Critical thinking as well as problem-solving skills should be developed to evolve their simplistic selfinstruction beliefs.

Learners' beliefs, which are formed through their experiences, guide them in their conceptualizations of language learning and influence the approaches they adopt to L2 learning. If they believe that languages can only be learned through translation and explanation, they will expect the language instruction to be based on translation and explanation and will reject any approach adopted by the teacher which does not correspond to this expectation (Abdolahzadeh \& Nia, 2014)

Therefore, to eliminate these wrong beliefs is a challenging task which needs a lot of efforts on the part of both learners and the teacher. Furthermore, they are formed as a result of the many years of the students' prior learning experience and some of them have even become theories the learners strongly believe of their usefulness as they have been validated by experience due to the erroneous teaching strategies followed by EFL teachers at schools and even sometimes at university (Abid, 2012).

Learners' beliefs are influenced by different language learning contexts. Future research should investigate how the language classroom as a social setting helps shaping students' beliefs about SLA and FLA and how students' beliefs about SLA and FLA, in turn, shape the interaction and actions that take place in the culture of the classroom. The same research can be carried out about teachers' beliefs.

\section{References}

Abdolahzadeh, E., \& Rajaee Nia, M. (2014). Language learning beliefs of Iranian learners: Examining the role of English language proficiency. Procedia Social and Behavioral Sciences, 98, 22-28. Abid, R. A. S. (2012). Investigating EFL Iraqi Learners' Beliefs about Learning English as a Foreign Language. Journal of the College of Arts, 6, 46-81.

Ahmad, I., Hussain, M. S., \& Radzuan, N. R. M. (2017). Teachers' Beliefs versus Learners' Beliefs in Grammar Teaching: Harmonizing Teaching and Learning for Adult Learners' Improved Proficiency in English. International Journal of Appled Linguistics and English Literature, 6(7), 130-142.

Ridha, N. S. A. (2014). Associations between EFL Learners' Beliefs about and their Strategy Use of Translation in English Learning: The Case of Iraqi Learners. Journal of the College of Arts, (70), 31-53. 
Asbjornson, B. (1999). Do beliefs matter in language learning achievem ent? Temple University Japan Working Papers in Applied Linguistics, 14 (November). Bernet, E. (2004). Investigating Vietnamese ESL learners' beliefs about language learning. English Australia Journal, 21(2), 40-54.

Bernat, E. \& Gvozdenko, I. (2005). Beliefs about Language Learning: Current Knowledge, Pedagogical Implications, and New Research Directions. TESL-EJ, 9(1), 1-21. Bransford, J., Brown, A., \& Cocking, R. (2000). How People Learn: Brain, Mind, Experience, and School. National Academy Press: Washington DC..

Cantwell, R.H.(1998). The development of beliefs about learning from mid-to-late adolescence. Educational Psychology, 18(1), 27-39.

Chai, X. (2013). Do Learner Beliefs about Learning Matter in English Language Education? Malaysian Journal of ELT Research, 9(2), 19-35.

Erlenawati. (2002a). Beliefs about Language Learning: Indonesian Learners' Perspectives, and Some Implications for Classroom Practices. Australian Journal of Education, 46(3), 323-337.

Farhady, H. (2006). Classroom assessment: A plea for change. Twenty-five years of living with applied linguistics collection of articles, 47-61.Tehran: Rahnama Publication.

Farhady, H., \& Hedayati, H. (2009). Language assessment policy in Iran. Annual Review of Applied Linguistics, 29, 132-141. Fujiwara, T. (2014). Language Learning Beliefs of Thai EFL University Students: Variations Related to Achievement Levels and Subject Majors. Electronic Journal of Foreign Language Teaching, 11(2), 300-311.

Ghobadi Mohebi, S., \& Khodadady, E. (2011). Investigating university students' beliefs about language learning. RELC Journal, 42(3), 290-304. Hosenfeld, C. (1978). Learning about learning: Discovering our students' strategies. Foreign Language Annals. 9, 117-129.

Horwitz, E. K. (1987). Surveying student beliefs about language learning. In A. Wenden and J. Rubin (eds), Learner Strategies in Language Learning, 119-129. London, England: Prentice Hall.

Horwitz, E. K. (1988). Beliefs about Language Learning of Beginning University Foreign Language Students. The Modern Language Journal, 72(3), 283-294.

Hurd, S. (2003). Learner difference in independent language learning contexts. LLAS Center for Languages, Linguistics and Area Sstudies. Kalaja, P., \& Barcelos, A. N. F. (2003). Beliefs about SLA: New research approaches. Dordrecht: Kluwer Academic Publishers. Kara, A. (2009). The Effect of a "Learning Theories" Unit on Students' Attitudes Toward Learning. Australian Journal of Teacher Education, 34(3), 99-113.

Li, L. (2013). The complexity of language teachers' beliefs and practice: one EFL teacher's theories. The Language Learning Journal, 41(2), 175-191.

Mantle-Bromley, C. (1995). Positive Attitudes and Realistic Beliefs Links to Proficiency. Modern Language Journal, 79, 372-386.

Mohammadi, M., Birjandi, P., \& Maftoon, P. (2015). Learning Strategy Training and the Shift in Learners' Beliefs About Language Learning. SAGE Open, 5(2), 1-11. Mori, Y. (1999). Epistemological beliefs and language learning beliefs: What do language learners believe about their learning? Language Learning, 49(3), 377-415.

Razmjoo, S. A., \& Mavaddat, R. (2016). Understanding Professional Challenges Faced by Iranian Teachers of English. International Journal of English Linguistics, 6(3), 208-220. https://doi.org/10.5539/ijel.v6n3p208

Rotter, J. (1996). Generalized expectancies for internal versus external control of reinforcement. Psychol Monogr, 80(1), 1-28. Sakui, K., \& Gaies, S. (1999). Investigating Japanese learners' beliefs about language learning. System, 27(4), 473-492.

Tsai, C., \& Kuo, P. (2008). Cram School Students' Conceptions of Learning and Learning Science in Taiwan. International Journal of Science Education, 30(3), 353-375.

Tudor, (1996). Learner-centredness in language education. Cambridge: Cambridge University Press.

Wahyudi, R. (2014). What Does Good Language Learner (GLL) Say about Foreign Language Learning? A Story from an Indonesian Learner. Advances in Language and Literary Studies, 5(1), 1-5. Wang, J., Spencer, K., \& 
Xing, M. (2009). Metacognitive beliefs and strategies in learning Chinese as a foreign language.System, 37(1), 46-56.

Wenden, A. (1986). Helping language learners think about learning. ELT Journal, 40(1), 3-12. Wenden, A. (1987). How to be a successful language learner: Insights and prescriptions from L2 learners. Learner Strategies in Language Learning. In A. Wenden \& J. Rubin (Eds.), Learner strategies in language learning (pp.103-117). Englewood Cliffs, NJ: Prentice Hall.

Wenden, A. L., ( 1999 ). An Introduction to Metacognitive Knowledge and Beliefs in Language Learning : Beyond the Basics. System, 27, $435-441$.

White, C. (1999). Expectations and emergent beliefs of self-instructed language learners. System, 27(4), 443-457.

Yang, N. (1999). The relationship between EFL learners' beliefs and learning strategy use. System, 27(4), 515535.Yu, X. (2007). A Survey on the Relationship between Learning Beliefs and Learning Strategies. US-China Education Review, 4(1), 58-61. 